\title{
Identifikasi Peran Kelembagaan Dalam Kegiatan Pariwisata Kabupaten Tabalong
}

\author{
Identification of Institutional Roles in Tourism Activities Kabupaten \\ Tabalong
}

\author{
Romi Alfianor ${ }^{\mathrm{a}}$, Nur Annadia Safitri ${ }^{\mathrm{a}}$, Afifatul Hidayati ${ }^{\mathrm{a} *}$ \\ ${ }^{a}$ Institut Teknologi Kalimantan, Balikpapan, Indonesia
}

\begin{abstract}
Abstrak
Kabupaten Tabalong memiliki 35 objek wisata. Jenis-jenis wisata yang ada terdiri dari wisata alam, wisata buatan dan wisata budaya. Setiap objek wisata memiliki lembaga yang berbeda, lembaga dalam mendukung kegiatan pariwisata di Kabupaten Tabalong terdiri dari pemerintah daerah, sektor wisata, dan masyarakat sekitar pariwisata. Pemerintah daerah memiliki peran mengatur, menyediakan dan mengalokasikan berbagai infrastruktur terkait kebutuhan pariwisata. Sektor swasta memiliki peran dalam membantu pemerintah, pemeliharaan dan pendanaan dalam meningkatkan kualitas pariwisata. Masyarakat memiliki peran sebagai lembaga yang tidak resmi. Berdasarkan hasil analisis jejaring sosial hubungan antar lembaga dapat diketahui bahwa masyarakat sebagai lembaga yang paling berpengaruh terhadap kegiatan wisata di Kabupaten Tabalong.
\end{abstract}

Kata kunci: Pariwisata; Kelembagaan ; Atraksi.

\begin{abstract}
Tabalong Regency has 35 tourist destinations. The types of tourism available consist of nature tourism, artificial tourism, and cultural tourism. Each touris attraction has a different manager. Institutions in supporting tourism activities in Tabalong Regency consist of local government, private sector, and tha community around tourism. Local governments have the role of regulating, providing and allocating varios infrastructures related tourism needs. The private sector has a role in helping depelopment, maintenance, and funding in improving the quality of tourism. The community acts as an unofficial manager of a tourist attraction that does not yet have a manager. Based on the results of the social network anakysis of interagency relation, it can be seenthe community has the most influential institution on the touris activities of the Tabalong Regency.
\end{abstract}

Keyword: Tourism; Institutional; Attraction.

\section{Pendahuluan}

Pariwisata berperan dalam meningkatkan pertumbuhan ekonomi, menciptakan lapangan pekerjaan, dan mengurangi kemiskinan. Indonesia memiliki sumber daya alam, manusia dan budaya yang melimpah dan tersebar luas di berbagai daerah. Hal tersebut menjadikan Indonesia berpontensi dikembangkan pariwisatanya, namun potensi yang ada belum dioptimalkan. Untuk mengoptimalkan potensi yang ada, diperlukan kerjasama antara pemangku kepentingan pariwisata, masyarakat, serta wisatawan. Berdasarkan 4 pilar pembangunan kepariwisataan, kelembagaan merupakan salah satu pilar dalam pembangunan kepariwisataan. Sehingga

\footnotetext{
* Corresponding author. Nur Annadia Safitri

E-mail address:08161058@student.itk.ac.id
} 
kelembagaan pariwisata dibutuhkan dalam pengembangan sektor pariwisata. Kelembagaan dalam pariwisata merupakan komponen penting dalam menunjang keberhasilan pariwisata. Kelembagaan berperan dalam mengatur sumberdaya dan distribusi manfaat dalam upaya peningkatan potensi pariwisata (Triambodo \& Damanik, 2015). Selain itu, kelembagaan dalam pariwisata berperan sebagai wadah sekaligus penggerak dalam memfasilitasi, dan mengembangkan partisipasi masyarakat dalam bidang pariwisata. Kelembagaan dalam pariwisata ada 3, yaitu pemerintah, sektor swasta dan masyarakat.

Berdasarkan Peraturan Daerah Provinsi Kalimantan Selatan Nomor 11 Tahun 2013, Kelembagaan pariwisata merupakan kesatuan unsur beserta jaringannya yang dikembangkan secara terorganisasi meliputi pemerintah, pemerintah daerah, swasta dan masyarakat, sumber daya manusia, regulasi dan mekanisme operasional yang secara berkesinambungan menghasilkan perubahan arah pencapaian tujuan di bidang kepariwisataan. Kabupaten Tabalong memiliki 35 objek daya Tarik wisata yang berpotensi untuk dikembangkan. Objek daya Tarik wisata yang terdapat di Kabupaten Tabalong dikelola oleh Lembaga pariwisata. Lembaga pariwisata yang terlibat dalam pengembangan pariwisata di Kabupaten Tabalong adalah pemerintah, swasta, dan masyarakat. Namun, Lembaga-lembaga pariwisata di Kabupaten Tabalong belum semua bekerjasama dalam pengelolaan maupun pengembangan objek daya Tarik wisata yang ada di Kabupaten Tabalong. Beberapa objek daya Tarik wisata yang berada di Kabupaten Tabalong yaitu Air terjun berangin, Air terjun lano, Air terjun tangkum, Batu pujung, DAM nalui, Danau undan, Danau tanjung puri indah, Danau sampalang, Gelar budaya dayah deah, Gua batu babi, Gua liang kantin, Makam penghulu rasyid, Makam syekh H.M.nafis ideras al-banjari, Makam batu puain, Masjid pusaka, Masjid pusaka nurul iman, Puncak karamo, Seribu cahaya badudus dan babarasih pusaka, Sirkuit marido, Sungai batu rapai, Sungai riam kinarum, Taman 10-k, Taman bunga poska, Taman bunga dan buah, Taman expo center, Taman tanjung bersinar park, Tabalong ethnic festival, Tari Balian Manaik Manau, Tugu obor, Upacara adat bakawinan bagunung perak dan Upacara membatur. Dari semua objek wisata tersebut hanya 4 objek wisata yang memiliki 2 lembaga pengelola yaitu Sirkuit marido, Tanjung Expo Center, Makam penghulu rasyid dan Masjid pusaka. Kemudian, sesuai peraturan daerah provinsi Kalimantan Selatan telah disebutkan bahwa Lembaga pariwisata harusnya dikembangkan secara terorganisir dari seluruh Lembaga maupun sumberdaya. Namun pada kenyataannya, perkembangan pariwisata belum optimal dari sisi koordinasi pemerintah dan masyarakat sehingga tujuan dalam mencapai kesejahteraan bagi masyarakat sekitar objek daya tarik wisata sulit dicapai.

Dari latar belakang di atas, dapat diketahui bahwa Lembaga-lembaga pariwisata harusnya saling bekerjasama dalam mengelola objek daya Tarik wisata yang ada. Sehingga dapat mencapai tujuan dalam bidang kepariwisataan seperti yang telah disebutkan dalam Peraturan Daerh Provinsi Kalimantan Selatan Nomor 11 Tahun 2013. Oleh karena itu, penelitian ini bertujuan untuk mengetahui hubungan Lembaga pariwisata yang ada di Kabupaten Tabalong.

\section{Metode}

Metode yang digunakan dalam penelitian ini adalah metode analisis deskriptif melalui pendekatan kuantitatif. Tujuan dari penelitian ini untuk menganalisis lembaga-lembaga yang berkaitan dengan perencanaan pariwisata Kabupaten Tabalong. Data yang dikumpulkan dalam penelitian ini yaitu pengumpulan data primer dan data sekunder. Data primer merupakan data yang didapatkan melalui tinjauan ke lapangan secara langsung. Sedangkan, pengumpulan data sekunder dilakukan dengan survey instansional untuk mendapatkan data koordinasi antar lembaga yang berkaitan dengan kegiatan pariwisata. Lembaga yang berperan dalah perencanaan pariwisata di Kabupaten Tabalong adalah lembaga pemeritah, swasta serta masyarakat. Dengan terlibatnya banyak lembaga dalam perencanaan pariwisata maka dibutuhkan kebijakan pariwisata agar tujuan dari peran serta kepentingan yang berbeda dapat menjadi satu.

Teknik analisis yang digunakan adalah analisis jejaring sosial yang merupakan suatu teknik untuk mempelajari hubungan atau relasi sosial antar anggota dari sebuah kelompok orang. Pemetaan pengetahuan dalam kerangka Social Network Analysis bisa divisualisasikan atau diwakilkan oleh bentuk matriks dan grafik. Social Network Analysis untuk mengetahui actor/nodes yang terlibat dan bagaimana hubungan terjadi. Dengan siapa aktor yang terhubung, seberapa kuat hubungan terjadi, seperti apa hubungan terjadi, apakah hubungan terjadi satu arah 
atau dua arah, bagaimana hubungan difasilitasi melalui media apa hubungan terjadi hingga ke aplikasi lainnya seperti siapa yang memiliki hubungan (ties) paling banyak, siapa yang terisolasi dalam network, bagaimana jarak (gap) dan rentang (length) antar masing-masing nodes. Tiga jenis sentralitas individu paling popular yaitu:

1. Degree centrality $=$ jumlah koneksi yang dimiliki sebuah node

2. Closseness centrality $=$ jarak rata-rata antara node dengan semua node yang lain $\mathrm{di}$ jaringan. Ukuran ini menggambarkan kedekatan node ini dengan node yang lain. Semakin dekat, semakin terhubung orang tersebut dengan lainnya.

3. Betweeness centrality = ukuran ini memperlihatkan peran sebuah node menjadi bottleneck. Semakin banyak jalan yang harus melewati persimpangan itu (misal tidak ada jalan alternative), maka semakin penting arti persimpangan tersebut.

\section{Kajian literatur}

\subsection{Kelembagaan Pariwisata}

Kelembagaan adalah keseluruhan pola-pola ideal, organisasi dan aktivitas yang berpusat di sekeliling kebutuhan dasar. Suatu lembaga dibentuk bertujuan untuk memenuhi berbagai kebutuhan manusia sehingga lembaga mempunyai fungsi. Lembaga juga merupakan konsep yang berpadu dengan struktur artinya tidak saja melibatkan pola aktivitas yang lahir dari segi sosial untuk memenuhi kebutuhan manusia, tetapi juga pola organisasi untuk melaksanakannya (Anantanyu, 2011). Menurut Undang-Undang No 10 Tahun 2009 wisata merupakan kegiatan perjalanan yang dilakukan oleh seseorang atau sekelompok orang dengan mengunjungi tempat untuk tujuan rekreasi dan mempelajari keunikan daya tarik wisata yang dikunjungi.

Dalam pengembangan pariwisata perlu memperhatikan kelembagaan, aspek kelembagaan merupakan komponen penting dalam menunjang keberhasilan pengembangan pariwisata. melalui upaya kelembagaan diharapkan pengembangan pariwisata dapat terus berjalan dan berkelanjutan (Triambodo dan Damanik, 2015). Dalam pengembangan ini perlu dilakukan kerjasama atau kemitraan melalui pendekatan dengan organisasi pariwisata yang ada terdiri dari pemerintah, swasta dan masyarakat serta pihak terkait yang diharapkan mendukung kelanjutan pembangunan pariwisata (Kurniawan,dkk, 2013). Menurut Pratama dan Iqbal (2018) terdapat tigas unsur dalam kelembagaan pariwisata yaitu.

1. Pemerintah

Pemerintah dalam hal ini mencakup keseluruhan lembaga politik dan sektor publik. Pemerintah berperan sebagai penyedia layanan publik, penyelenggaraan pemerintahan, dan membangun lingkungan yang kondusif untuk mencapai tujuan pembangunan yang baik.

2. Sektor Swasta

Pelaku sektor swasta mencakup perusahaan yang aktif dalam sistem pasar, seperti industri pengolahan, perdagangan, jasa dan kegiatan sektor swasta informal lainnya. Sektor swasta sangat berperan penting dalam meningkatkan produktivitas, penyerapan tenaga kerja, sumber penerimaan, investasi public, pengembangan usaha dan pertumbuhan ekonomi

3. Masyarakat

Masyarakat merupakan perseorangan atau kelompok yang berinteraksi secara sosial, politik dan ekonomi. Masyarakat tidak hanya berperan sebagai check and balance terhadap kewenangan dan kekuasaan pemerintah dan sektor swasta. Masyarakat juga berperan memantau kinerja kedua stakeholder lainnya.

\subsection{Social Network Analysis (SNA)}

Analisis jejaring sosial merupakan suatu teknik untuk mempelajari hubungan atau relasi sosial antar anggota dari sebuah kelompok orang. Pemetaan pengetahuan dalam kerangka Social Network Analysis bisa divisualisasikan atau diwakilkan oleh bentuk matriks dan grafik. Dalam analisis jejaring sosial, ada beberapa ukuran dasar yang menjadi titik tolak perhitungan matematis untuk mengetahui pola keterhubungan dalam jejaring tersebut. 


\section{Hasil dan Pembahasan}

Hasil yang didapatkan berupa peran masing-masing lembaga yaitu instansi pemerintah, sektor swasta dan masyarakat terhadap aktivitas pariwisata di Kabupaten Tabalong.

\subsection{Instansi Pemerintah}

Pemerintah memiliki otoritas dalam pengaturan, penyediaan dan peruntukan berbagai infrastruktur terkait kebutuhan pariwisata. Instansi Pemerintah yang berperan dalam perencanaan pariwisata di Kabupaten Tabalong adalah Dinas Pemuda, Olahraga, dan Pariwisata (Disporapar) Kabupaten Tabalong. Disporapar Kabupaten Tabalong berperan dalam pengelolaan objek pariwisata yang ada di Kabupaten Tabalong. Disporapar Kabupaten Tabalong memiliki berbagai pengaruh dan kepentingan, terutama dalam bidang pariwisata. Adapun tugas pokok dan fungsi Disporapar Kabupaten Tabalong adalah melaksanakan kebijakan daerah di bidang pemuda, olahraga, kebudayaan, sarana penunjang pariwisata, promosi dan informasi pariwisata. Dalam pengelolaan pariwisata, Objek Daya Tarik Wisata (ODTW) yang terdiri dari jenis wisata alam, wisata buatan, dan wisata budaya. Adapun nama masing-masing ODTW yang dikelola oleh Disporapar Kabupaten Tabalong adalah Danau Undan, Gunung Sialing, Danau Sampalang, Puncak Karamo, Sungai Batu Rapai, Goa Batu Babi, Goa Liang Kantin, Sungai Riam Kinarum, Sirkuit Marido, Taman 10-K, Taman Tanjung Bersinar Park, Tanjung Expo Center, Tugu Obor, DAM Nalui, Taman Giat, Makam Penghulu Rasyid, Masjid Pusaka Banua Lawas, Makam Syekh Nafis, Islamic Center Kabupaten Tabalong, Makam Datu Puain, Masjid Pusaka Nurul Iman, Tabalong Ethnic Festival, Tarian Balian Manaik Manau.

\subsection{Swasta}

Lembaga swasta yang berperan dalam perencanaan pariwisata di Kabupaten Tabalong adalah PT. East West Seed Indonesia, PT. Adhi Karya, Lembaga Pengelola Hutan Desa Maju Bersama, dan Tabalong Otomotif Club (TOC). PT. East Seed West Need Indonesia berperan dalam membantu penyediaan bibit tanaman pada objek wisata Taman Bunga dan Buah yang terdapat di Kecamatan Pugaan. PT. Adhi Karya berperan dalam penataan wisata Sungai Riam Kinarum Indah yang terdapat di Kecamatan Upau. Lembaga Pengelola Hutan Desa Maju Bersama berperan dalam penataan dan perawatan objek wisata Air Terjun Lano, dan TOC berperan dalam perawataan objek wisata Sirkuit Marido.

\subsection{Masyarakat}

Masyarakat yang tinggal di sekitar objek wisata di Kabupaten Tabalong berperan aktif dalam perencanaan pariwisata. Masyarakat berperan dalam perlindungan dan pengamanan objek wisata yang ada di Kabupaten Tabalong. Untuk saat ini, di Kabupaten Tabalong belum ada kelompok sadar wisata (Pokdarwis) untuk mengelola objek wisata yang ada di Kabupaten Tabalong. Masyarakat dengan sukarela mengelola objek wisata yang ada dibantu oleh Pemerintah setempat. Masyarakat juga berperan dalam penyediaan atraksi wisata, akomodasi, serta jasa pemandu wisata. Dalam pengelolaan pariwisata, masayarakat setempat mengelola ODTW yaitu Air Terjun Tangkum, Wisata Batu Pujung, Air Terjun Tabur Berangin, Goa Liang Tapah, Taman Bunga Poska, Danau Tanjung Puri Indah. 


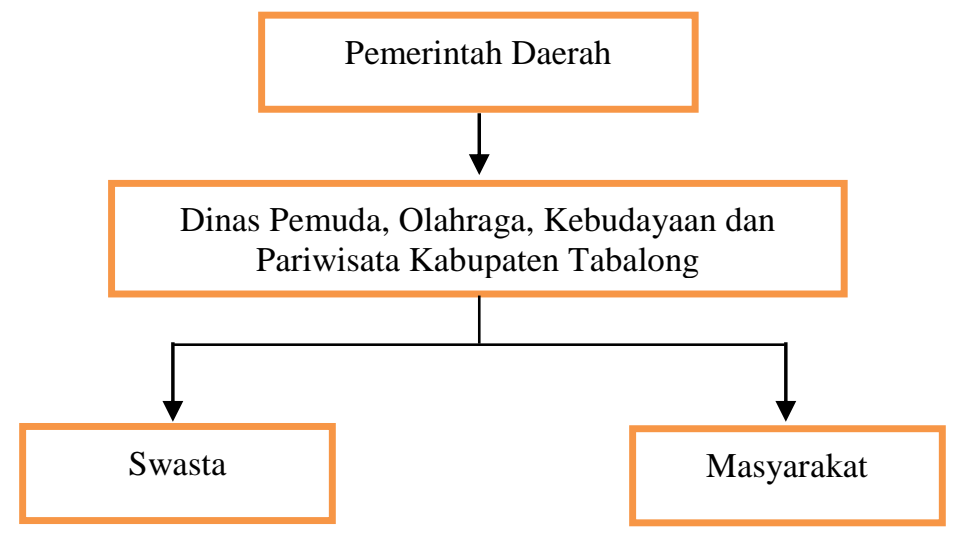

Gambar 1. Skema Kelembagaan Pariwisata Kabupaten Tabalong (Analisis, 2019)

Setelah diketahui lembaga-lembaga yang terlibat dalam pengelolaan pariwisata di Kabupaten Tabalong, maka dilakukan analisis jaringan sosial (Social Network Analysis) untuk mengetahui hubungan kelembagaan dalam pengelolaan pariwisata di Kabupaten Tabalong. Berikut merupakan tabel terkait lembaga pengelola pada 35 ODTW yang terdapat di Kabupaten Tabalong yang akan menjadi acuan dalam melakukan analisis jaringan sosial.

Tabel 1. Lembaga Pengelola Objek Wisata di Kabupaten Tabalong (Penulis, 2019)

\begin{tabular}{|c|c|c|c|c|c|c|c|c|c|c|c|c|c|c|c|c|c|}
\hline \multirow{2}{*}{ Kelembagaan } & \multicolumn{17}{|c|}{ Objek Wisata } \\
\hline & & $\mathbf{A}$ & B & $\mathrm{C}$ & D & $\mathbf{E}$ & $\mathbf{F}$ & G & $\mathbf{H}$ & I & $\mathbf{K}$ & $\mathbf{L}$ & $\mathbf{M}$ & $\mathbf{N}$ & $\mathbf{O}$ & $\mathbf{Q}$ & $\overline{\mathbf{R}}$ \\
\hline Pemerintah & & 1 & 0 & 0 & 1 & 1 & 0 & 1 & 0 & 1 & 1 & 1 & 0 & 0 & 0 & 0 & 1 \\
\hline Swasta & & 0 & 0 & 0 & 0 & 0 & 1 & 0 & 0 & 0 & 0 & 0 & 1 & 0 & 0 & 0 & $\overline{0}$ \\
\hline Masyarakat & & 0 & 1 & 1 & 0 & 0 & 0 & 0 & 1 & 0 & 0 & 0 & 0 & 1 & 1 & 1 & $\overline{0}$ \\
\hline \multirow{2}{*}{ Kelembagaan } & \multicolumn{17}{|c|}{ Objek Wisata } \\
\hline & $\mathbf{S}$ & $\mathbf{T}$ & $\mathbf{U}$ & $\mathbf{V}$ & $\mathbf{W}$ & $\mathbf{X}$ & $\mathbf{Y}$ & $\mathbf{Z}$ & $\mathbf{A A}$ & $\mathbf{A B}$ & $\overline{A C}$ & AD & $\mathbf{A E}$ & $\mathbf{A F}$ & AG & $\mathbf{A H}$ & $\overline{\text { AI }}$ \\
\hline Pemerintah & 1 & 1 & 1 & 1 & 0 & 1 & 1 & 1 & 1 & 1 & 1 & 0 & 0 & 1 & 1 & 0 & 0 \\
\hline Swasta & 0 & 0 & 0 & 0 & 1 & 0 & 0 & 0 & 0 & 0 & 0 & 0 & 0 & 0 & 0 & 0 & 0 \\
\hline Masyarakat & 1 & 0 & 0 & 0 & 0 & 1 & 1 & 0 & 0 & 0 & 0 & 1 & 1 & 0 & 0 & 1 & 1 \\
\hline
\end{tabular}

Keterangan:

0 : Tidak Ada

$1:$ Ada

A : Danau Undan

B : Air Terjun Tangkum

C : Batu Pujung

D : Gunung Sialing

E : Air Terjun Berangin

$\mathrm{F}$ : Air Terjun Lano

G : Danau Sampalang

$\mathrm{H}$ : Gua Liang Tapah

I : Puncak Karamo

J : Sungai Batu Rapai

K : Gua Batu Babi

L : Gua Liang Kantin

M: Sungai Riam Kinarum

$\mathrm{N}$ : Taman Bunga Poska

$\mathrm{O}$ : Danau Tanjung Puri Indah

$\mathrm{P}$ : Sirkuit Marido

S : Tanjung Expo Center

$\mathrm{T}$ : Tugu Obor

U : Dam Naluai

$\mathrm{V} \quad$ : Taman Giat

W : Taman Bunga dan Buah

X : Makam Penghulu Rasyid

Y : Masjid Pusaka

Z : Makam Syekh H.M. Nafis Ideras Al-Banjari

AA : Masjid Islamic Center Kabupaten Tabalong

AB : Makam Datu Puain

AC : Masjid Pusaka Nurul Iman

AD : Gelar Budaya Dayah Deah

AE : Seribu Cahaya Badudus \& Babarasih Pusaka

AF : Tabalong Ethnic Festival

AG : Tari Balian Manaik Manau

AH : Upacara Adat Bakawinan Bagunung Perak 
Q : Taman 10-k

$\mathrm{R}$ : Taman Tanjung Bersinar Park

AI : Upacara Membatur

Berikut merupakan hasil dari analisis jaringan sosial berdasarkan tabel lembaga pengelola ODTW di Kabupaten Tabalong.

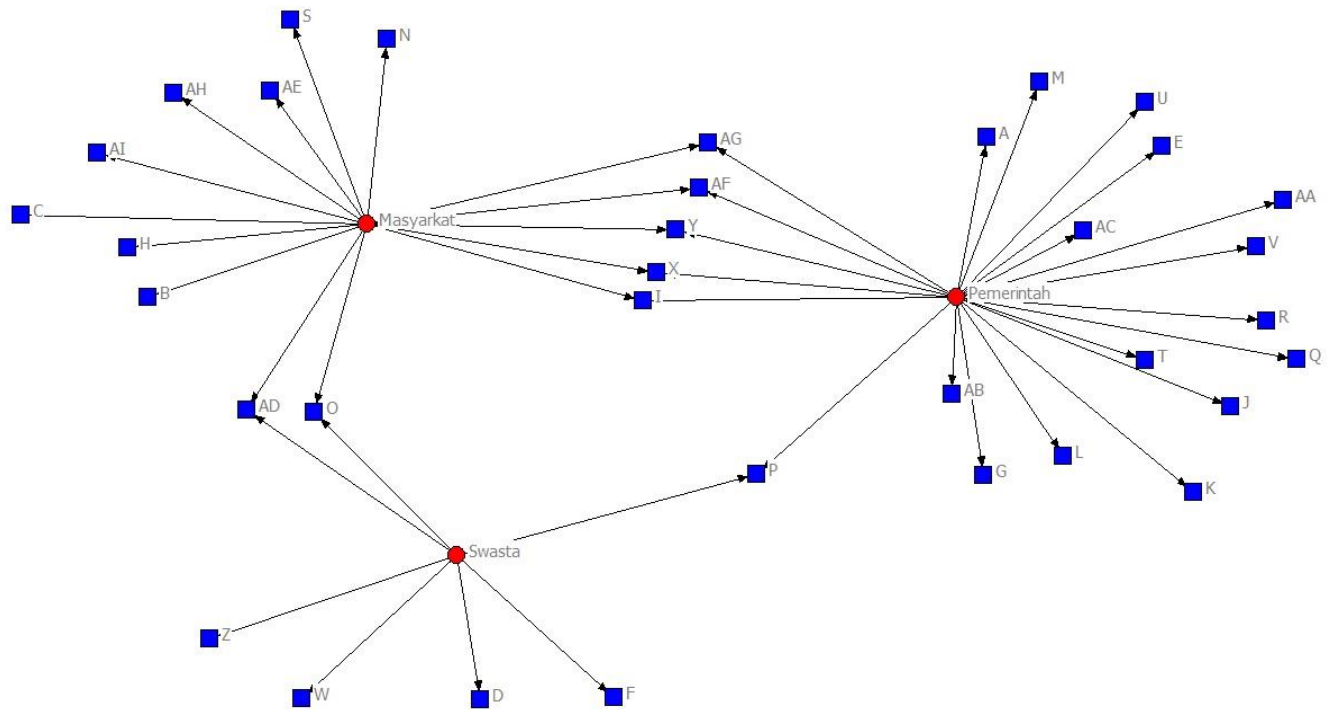

Gambar 2. Hubungan Kelembagaan dalam Pengelolaan Pariwisata (Analisis, 2019)

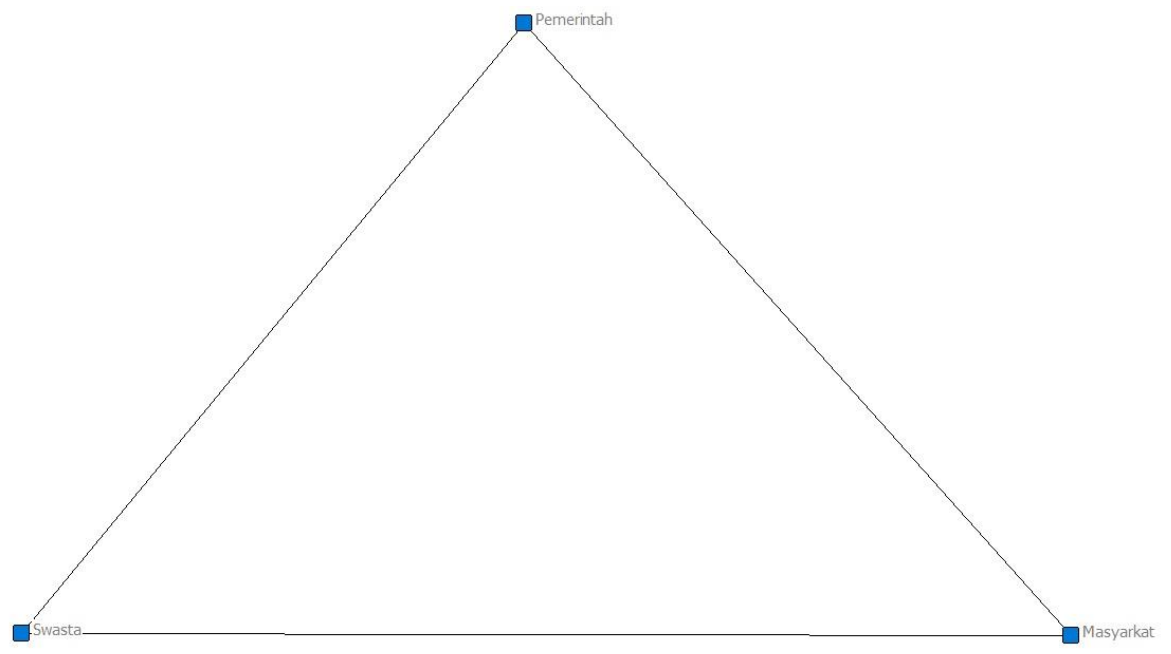

Gambar 3. Hubungan Antar Kelembagaan Pengelola Pariwisata (Analisis, 2019)

Berdasarkan hasil analisis jaringan seperti pada gambar 1 diatas, didapatkan bahwa Pemerintah, Swasta dan masyarakat merupakan kelembagaan memiliki peran penting dalam pengelolaan pariwisata di Kabupaten Tabalong. Pada ODTW yang terdapat di Kabupaten Tabalong lebih banyak dikelola oleh pemerintah dan masyarakat. Hanya beberapa ODTW saja yang dikelola oleh swasta. Tak hanya itu, ada beberapa ODTW yang dikelola oleh pemerintah dan masyarakat, pemerintah dan swasta, bahkan swasta dan pemerintah. pada gambar 2 dalam hubungan antar kelembagaan pengelola pariwisata yang ada di Kabupaten Tabalong, Pemerintah memiliki kedudukan tertinggi dalam pengelolaan pariwisata di Kabupaten Tabalong. Berikut hubungan kelembagaan pengelola pariwisata digambarkan dalam diagram vein. 


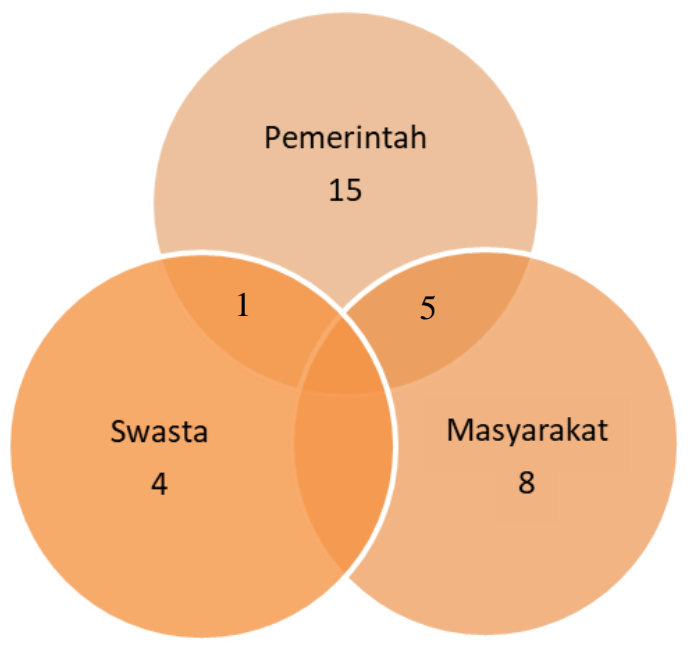

Gambar 4. Diagram Vein Keterkaitan Lembaga Pengelola Objek Daya Tarik Wisata Kabupaten Tabalong (Analisis, 2019)

Setelah itu, dilakukan perhitungan untuk mengetahui tingkat hubungan kelembagaan pariwisata di Kabupaten Tabalong dengan hasil sebagai berikut.

Tabel 2. Hasil Perhitungan Analisis Tingkat Hubungan Kelembagaan (Analisis, 2019)

\begin{tabular}{clrrr}
\hline No. & Kelembagaan & \multicolumn{1}{c}{ Degree } & Closeness & \multicolumn{1}{c}{ Betweeness } \\
\hline 1. & Pemerintah & 6.000 & 2.000 & 0.000 \\
2. & Swasta & 3.000 & 2.000 & 0.000 \\
3. & Masyarakat & 7.000 & 2.000 & 0.000 \\
\hline
\end{tabular}

Pada tabel diatas terdapat tiga kategori dari hasil perhitungan analisis tingkat hubungan kelembagaan pariwisata di Kabupaten Tabalong, yaitu Degree, Closseness, dan Betweness. Degree merupakan lembaga yang paling berpengaruh terhadap lembaga lainnya, Closseness merupakan lembaga yang berperan sebagai penyampai informasi, dan Betweness merupakan lembaga yang berperan sebagai perantara penyampaian informasi. Hasil nilai degree didapatkan dari hasil identifikasi setiap objek daya tarik wisata terhadap pihak pengelola, yang mana nilai pada tabel diatas diketahui bahwa lembaga yang paling berpengaruh terhadap lembaga lainnya adalah masyarakat dengan nilai degree 7 . Pada nilai closeness, ketiga lembaga mendapatkan nilai yang sama, sehingga ketiga kelembagaan tersebut sama-sama berperan sebagai penyampai informasi dengan nilai 2. Dari tabel diatas dapat diketahui pula, bahwa dari ketiga lembaga tersebut tidak ada yang berperan sebagai perantara penyampai informasi karena memiliki nilai 0 .

\section{Kesimpulan}

Kegiatan pariwisata Kabupaten Tabalong yang ditinjau dari tingkat hubungan antar stakeholder memiliki beberapa keterkaitan dalam pengelolaannya. Peran dari masyarakat sekitar wisata di Kabupaten Tabalong memiliki peran sebagai lembaga yang paling berpengaruh terhadap pengelolaan pariwisata dengan nilai degree 7. Masing-masing lembaga baik pihak pemerintah, pihak swasta, dan masyarakat yang mengelola kegiatan pariwisata Kabupaten Tabalong sama-sama berperan sebagai penyampai informasi pariwisata. Seluruh lembaga tidak ada yang menjadi perantara penyampaian informasi pariwisata sehingga koordinasi antar lembaga dapat dikatakan sudah baik dalam kegiatan pariwisata Kabupaten Tabalong. Dari peneitian ini dapat diketahui lembaga pemerintah, swasta dan masyarakat memiliki keterlibatan yang sama dalam meningkatkan kegiatan pariwisata di Kabupaten Tabalong. 


\section{Referensi}

Anantanyu Sapja. (2011). Kelembagaan Petani: Peran dan Strategi Pengembangan Kapasitasnya. Universitas Sebelas Maret: Surakarta.

Id asep dan Wina Witanti. (2017). Analisis Jejaring Sosial Menggunakan Social Network Analysis untuk Membantu Social CRM bagi UMKM di Cimahi. Universitas Jenderal Achmad Yani: Cimahi.

Kurniawan Fandy, Soesilo Zauhar \& Hermawan. (2013). Kemitraan Pengelolaan Sektor Pariwisata (Studi Pada Tirta Wisata Kabupaten Jombang). Universitas Brawijaya: Malang.

Pratama Rhiki dan Mohammad Iqbal. (2018). Analisis Pemetaan Jejaring Stakeholder Pariwisata Di Kota Batu Dengan Menggunakan Metode Social Network Analysis (SNA). Universitas Brawijaya: Malang.

Putra, W. I. (2017). Peran Lembaga Adat Paser dalam pelestarian nilai-nilai sosial budaya lokal di Kabupaten Paser Kalimantan timur (Doctoral dissertation, Pascasarjana).

Riswan, M. (2018). Problematika Pengembangan Ekonomi Kreatif Dalam Menunjang Sektor Pariwisata Di Kalimantan Selatan. Jurnal Kebijakan Pembangunan, 13(2), 129-139.

Siska, D., Hadi, S., Firdaus, M., \& Said, S. (2015). Strategi Pengembangan Ekonomi Wilayah Berbasis Agroindustri di Kawasan Andalan Kandangan Kalimantan Selatan. Jurnal Bina Praja: Journal of Home Affairs Governance, 7(2), 99-110

Tampahan Binsar dan Dana Indra Sensuse. (2010). Pemetaan dan Analisis Knowledge Sharing Pada Situs Forum Komunitas Online Kaskus. Universitas Indonesia: Depok.

Triambodo, S. dan Damanik, J. (2015). Analisis Strategi Penguatan Kelembagaan Desa Wisata Berbasis Ekonomi Kreatif (Studi di Desa Wisata Kerajinan Tenun Dusun Gamplong, Desa Sumberrahayu, Kecamatan Moyudan, Kabupaten Sleman, DIY). Universitas Gadjah Mada: Yogyakarta.

Undang Undang Republik Indonesia Nomor 10 Tahun 2009 Tentang Kepariwisataan. Jakarta: Menteri Sekretaris Negara. 